\title{
MOISTURE AND THERMAL TRANSPORT PROPERTIES OF DIFFERENT POLYESTER WARP-KNITTED SPACER FABRIC FOR PROTECTIVEAPPLICATION
}

\author{
Qing Chen ${ }^{1}$, Dahua Shou ${ }^{2 *}$, Rong Zheng ${ }^{1}$, Ka-Po Maggie Tang ${ }^{2}$, Bailu Fu', Xiaoting Zhang ${ }^{3}$, Pibo $\mathrm{Ma}^{4}$ \\ 1 Shanghai International Fashion Innovation Center, Donghua University \\ 2 Institute of Textiles and Clothing, The Hong Kong Polytechnic University \\ 3 School of Digital Media, Jiangnan University \\ 4 The School of Textiles and Clothing, Jiangnan University \\ ${ }^{*}$ Corresponding author. E-mail: dahua.shou@polyu.edu.cn
}

\begin{abstract}
:
Warp-knitted spacer fabrics are generally used for sportswear, functional clothing, protective clothing, and other applications. This article studied the heat and mass transfer properties of polyester warp-knitted spacer fabrics from low thickness $(2 \mathrm{~mm})$ to high thickness $(20 \mathrm{~mm})$, from low mass $(247.34 \mathrm{~g} / \mathrm{m} 2)$ to high mass $(1,585.9 \mathrm{~g} / \mathrm{m} 2)$, and surface structure in plain or mesh construction. Water vapor permeability, air permeability, water absorption, and thermal insulation property were conducted to evaluate the spacer fabrics. The results revealed that with increasing volume density the water vapor permeability of spacer fabrics decreased, but the water absorption ratio increased. The water vapor permeability of fabrics increased when thickness decreased and volume density increased. It was further found that spacer fabrics with mesh worn nearby the skin and plain structure worn far from the skin could facilitate water vapor and air transmission. The difference of $8.82 \%$ for water vapor permeability and $14.19 \%$ for air permeability were found between testing mesh side up and down for the spacers ( 2.56 and $3.37 \mathrm{~mm}$ ), respectively. Thermal insulation ratio was highly and significantly correlated with heat transfer coefficient at -0.958 and with thickness at 0.917. Thermal insulation ratio is highly and significantly correlated with air permeability at 0.941.
\end{abstract}

\section{Keywords:}

Warp-knitted spacer fabrics, water vapor permeability, air permeability, water absorption, thermal insulation

\section{Introduction}

Knitted spacer fabrics with three-dimensional (3D) structure are widely used for clothing, mattress, and textile composite material. Due to its higher thickness, higher structure stability, and better compression recovery, warp-knitted spacer fabrics were most widely used in various technical applications while weft-knitted spacer fabrics were used for cushions, protection of the human body from injuries, energy absorption [1], and advanced wound dressing [2]. Many studies focused on the mechanical property of spacer fabric, such as compression behavior of weft-knitted spacer [3], compression fatigueresistance property of warp-knitted spacer [4], sound absorption behavior [5], and stab-resistance property [1].

Besides, some circular- and flat-knitted spacer were developed and evaluated in different aspects. Flat-knitted spacer fabrics with $2.14-4.05 \mathrm{~mm}$ thickness were produced with various yarn and fabric structure combinations using different raw materials on both layers [6]. The inner layer, worn next to the skin, was constructed with soy protein yarns and the reverse layer with polyester, polyamide, and polypropylene yarns. Cotton/bamboo-blended and polyamide yarn were used for the production of interlock and flat-knitted spacer fabrics with 1.8-3.1 $\mathrm{mm}$ thickness for shoe linings [7].
The flat-knitted spacer fabrics with thickness from 8.2 to $11.9 \mathrm{~mm}$ were made with different connecting distances of monofilament yarn and different surface materials [8]. The fabric containing Coolmax ${ }^{\circledR}$ yarn exhibited better thermal-physiological comfort properties. The effects of fabric parameter on comfort-related properties were studied as for circular-knitted spacer fabrics with 2.2-3.5 mm thickness [9]. It was observed that fabric weight, thermal conductivity, thermal resistivity, air permeability, and relative water vapor permeability properties were affected by dial height and the type of spacer yarn significantly.

The thermal insulation property of spacer fabric with wool fiber on its surface was studied [10]. Hydro-entangled wool fiber web-spacer fabrics had markedly reduced thermal conductivity. Bagherzadeh et al. manufactured a functional 3D warp-knitted spacer fabric with 3.0-3.1 mm containing highwicking materials. The fabric was aimed to be used for a snugfitting shirt worn under protective vest to absorb a user's sweat, in order to reduce the humidity and improve user's thermal comfort [11]. Water absorbency by knitted spacer structures with higher thickness at $9.1-13.3 \mathrm{~mm}$ was experimentally investigated using a gravimetric absorbency tester to record absorbency rate, total absorbency, and time taken to saturate the structure [12]. It was found that the total water absorbed by a knitted structure depended on the porosity and other characteristics of the structure. Generally, knitted structures with high porosity absorb more water than those with low porosity. Four spacer fabrics with thickness at 2.9-4.7 mm were 
studied in terms of moisture transport property computationally and experimentally [13]. The important parameters in moisture transfer were porosity and air permeability. The thermal and water vapor transmission of warp-knitted 3D spacer fabrics with thickness at 1.6-7.29 mm for car upholstery applications was studied [14].

Spacer fabrics made up of polyester or meta-aramid filament yarns with different linear densities were investigated. The fabrics were produced with different structures, such as lock knit, single-sided hexagonal mesh, and double-sided hexagonal mesh. The raw materials, type of spacer yarn, density, thickness, and tightness of surface layer have significant influence on thermal conductivity in spacer fabrics. The parameters that mainly influence the water vapor permeability of these fabrics are porosity, density, and thickness. Since those studies were conducted only on the specific spacer fabric with narrow range of thickness, the conclusions were restricted to a certain extent. Besides, the effect of surface structure on the water vapor permeability and air permeability was not studied.

Hence, this study investigated the thermo-physiological properties of different spacer fabrics. The fabrics had mass around $247.34-1,585.9 \mathrm{~g} / \mathrm{m}^{2}$, thickness around 2-20 mm, and plain, mesh, and spacer structures. Water vapor permeability, air permeability, water absorption, and thermal insulation tests were conducted. Besides, this study compared not only the normal warp-knitted fabrics and warp-knitted spacer fabrics but also within different spacer fabrics. Due to the higher thickness of spacer fabric compared with traditional fabric, this study also investigated the water vapor and air permeability when fabrics were placed with mesh up or down separately. Pearson correlation analysis and principal component analysis (SPSS) were used to find the relationship between fabric parameter and testing results, and to extract the significant factor to determine the spacer with best heat and moisture transfer property.

\section{Experiment}

\subsection{Sample}

Nine polyester warp-knitted spacer fabrics (nos. 4-12) varied in surface structure, thickness, and weight were studied. Also, three single-layered warp-knitted polyester fabrics (nos. 1-3) in mesh or plain structure were included as reference. The images of these samples were summarized in Figure 1. The fabric parameters were listed in Table 1 . The details of knitting notation and yarn were summarized in Table 2.

Fabric no. 1 was in mesh structure. Fabric nos. 2 and 3 were in plain structure with different masses. Fabric nos. 4 and 6-8 had mesh structure on the one surface and plain structure on the other surface. Fabric nos. 9, 11, and 12 had mesh structure on both sides.

The mass of fabric no. $1\left(83.82 \mathrm{~g} / \mathrm{m}^{2}\right)$ was the lowest one owing to its large mesh. Fabric nos. 4 and 5 were similar in mass (247.37 and $257.5 \mathrm{~g} / \mathrm{m}^{2}$, respectively). Fabric nos. $6-8$ were similar in mass $\left(433.0 \sim 484.9 \mathrm{~g} / \mathrm{m}^{2}\right)$. The mass of fabric nos. 11 and 12 was the highest $\left(1,569.86\right.$ and $1,585.90 \mathrm{~g} / \mathrm{m}^{2}$, respectively) due to the highest thickness.

The thickness of fabric no. $2(0.21 \mathrm{~mm})$ was the lowest one. The thickness of fabric nos. 9 and 10 was similar $(7.42 \sim 7.68 \mathrm{~mm})$, the fabric nos. 11 and 12 had the highest thickness $(20 \mathrm{~mm})$, and fabric nos. 4-8 had similar thickness (2.56 3.37 mm).

The volume densities of fabric nos. 4, 5, and 9 were similar $\left(92.63 \sim 100.00 \mathrm{~kg} / \mathrm{m}^{3}\right)$. Fabric nos. 7 and 8 had similar volume density at 159.22 and $166.63 \mathrm{~kg} / \mathrm{m}^{3}$, respectively. Fabric nos. 10 and 11 had similar volume density at 79.3 and $78.5 \mathrm{~kg} /$ $\mathrm{m}^{3}$, respectively. Fabric no. 12 had lowest volume density $\left(78.50 \mathrm{~kg} / \mathrm{m}^{3}\right)$. Fabric nos. 2 and 3 had comparable higher volume density, and the highest one was obtained in fabric no. $3\left(435.92 \mathrm{~kg} / \mathrm{m}^{3}\right)$.

Table 1. Fabric parameters

\begin{tabular}{|c|c|c|c|c|c|}
\hline No. & Mass $\left(g / m^{2}\right)$ & Thickness (mm) & Volume density $\left(\mathbf{k g} / \mathrm{m}^{3}\right)$ & $\begin{array}{l}\text { Loop density } \\
(\text { number/cm²) }\end{array}$ & Porosity (\%) \\
\hline 1 & 83.82 & 0.60 & 139.70 & 40 & 89.88 \\
\hline 2 & 84.18 & 0.21 & 400.86 & 448 & 70.95 \\
\hline 3 & 104.62 & 0.24 & 435.92 & 396 & 68.41 \\
\hline 4 & 247.34 & 2.56 & 96.62 & 150 & 93.00 \\
\hline 5 & 257.50 & 2.78 & 92.63 & 300 & 93.29 \\
\hline 6 & 433.00 & 3.37 & 128.49 & 135 & 90.69 \\
\hline 7 & 456.95 & 2.87 & 159.22 & 144 & 88.46 \\
\hline 8 & 484.90 & 2.91 & 166.63 & 49 & 87.93 \\
\hline 9 & 742.02 & 7.42 & 100.00 & 20 & 92.75 \\
\hline 10 & 910.00 & 7.68 & 118.49 & 56 & 91.41 \\
\hline 11 & $1,585.9$ & 20.00 & 79.30 & 50 & 94.25 \\
\hline 12 & $1,569.8$ & 20.00 & 78.50 & 45 & 94.31 \\
\hline
\end{tabular}


Table 2. Details of knitting structure and yarn

\begin{tabular}{|c|c|c|}
\hline Sample & Knitting notation and yarn threading & Material \\
\hline 1 & $\begin{array}{l}\text { GB1:1-0/1-2/1-0/1-2/2-3/2-1/2-3/2-1//1in1out; } \\
\text { GB2:2-3/2-1/2-3/2-1/1-0/1-2/1-0/1-2//1out1 in. }\end{array}$ & $\begin{array}{l}\text { 75D36f polyester } \\
\text { 75D36f polyester }\end{array}$ \\
\hline 2 & $\begin{array}{l}\text { GB1:1-0/1-2//Full in; } \\
\text { GB2:2-3/1-0//Full in. }\end{array}$ & $\begin{array}{l}\text { 75D36f polyester } \\
\text { 75D36f polyester }\end{array}$ \\
\hline 3 & $\begin{array}{l}\text { GB1:1-0/1-2//Full in; } \\
\text { GB2:3-4/1-0//Full in. }\end{array}$ & $\begin{array}{l}\text { 75D36f polyester } \\
\text { 75D36f polyester }\end{array}$ \\
\hline 4 & $\begin{array}{l}\text { GB1:1-0-2-2/2-3-0-0//1in1out; } \\
\text { GB2:2-3-2-2/1-0-0-0//1in1out; } \\
\text { GB3: 1-0-1-2/2-3-2-1//; } \\
\text { GB4: 2-3-2-1/1-0-1-2//; } \\
\text { GB5:1-0-1-2/2-3-2-1//Full in, } \\
\text { GB6:0-0-1-0/2-2-1-2//Full in; } \\
\text { GB7:0-0-1-0/2-2-1-2//Full in. }\end{array}$ & $\begin{array}{l}\text { 30D polyester } \\
\text { 30D polyester } \\
\text { 200D36f polyester } \\
\text { 200D36f polyester } \\
\text { 30D polyester monofilament } \\
\text { 75D36f polyester } \\
\text { 75D36f polyester }\end{array}$ \\
\hline 5 & $\begin{array}{l}\text { GB1:1-2-1-1/1-0-1-1//Full in; } \\
\text { GB2:1-0-1-2/2-3-2-1//Full in; } \\
\text { GB3:1-1-1-0/1-1-1-2//Full in. }\end{array}$ & $\begin{array}{l}\text { 75D36f polyester } \\
\text { 30D polyester monofilament } \\
\text { 75D36f polyester }\end{array}$ \\
\hline 6 & $\begin{array}{l}\text { GB1: } 0-1-1-1 / 1-0-0-0 / / 3 \text { in1out; } \\
\text { GB2: } 0-0-0-0 / 5-5-5-5 / / 3 \text { in1out; } \\
\text { GB3: } 1-0-1-2 / 2-3-2-1 / / \text { Full in; } \\
\text { GB4: } 1-1-1-0 / 1-1-1-2 / / \text { Full in. }\end{array}$ & $\begin{array}{l}\text { 150D72f polyester } \\
\text { 150D72f polyester } \\
\text { 30D polyester monofilament } \\
\text { 75D36f polyester }\end{array}$ \\
\hline 7 & $\begin{array}{l}\text { GB1: } 1-0-0-0 / 2-3-2-2 / 4-5-4-4 / 3-2-2-2 / / 2 \text { in2out; } \\
\text { GB2: 4-5-0-0/3-2-2-2/1-0-0-0/2-3-2-2//1out2in1out; } \\
\text { GB3: 1-0-1-2/2-3-2-1//Full in; } \\
\text { GB4: } 1-1-1-0 / 1-1-1-2 / / F u l l ~ i n ; \\
\text { GB5: } 1-1-1-2 / 1-1-1-0 / / F u l l ~ i n .\end{array}$ & $\begin{array}{l}\text { 100D36f polyester } \\
\text { 100D36f polyester } \\
\text { 30D polyester monofilament } \\
\text { 100D36f polyester } \\
\text { 100D36f polyester }\end{array}$ \\
\hline 8 & $\begin{array}{c}\text { GB1: 1-0-0-0/2-3-2-2/4-5-0-0/3-2-2-2//2 in2out; } \\
\text { GB2: 4-5-0-0/3-2-2-2/1-0-0-0/2-3-2-2//1out2in1out; } \\
\text { GB3: 1-0-1-2/2-3-2-1//Full in; } \\
\text { GB4: 1-1-1-0/1-1-1-2//Full in. }\end{array}$ & $\begin{array}{l}\text { 300D72f polyester } \\
\text { 300D72f polyester } \\
\text { 140D polyester monofilament } \\
\text { 75D36f polyester }\end{array}$ \\
\hline 9 & $\begin{array}{l}\text { GB1:1-0-0-0/1-2-2-2/1-0-0-0/1-2-2-2/2-1-1-1/1-2-2-2/3-2-2-2/2-1-1-1/3-2-2- } \\
\text { 2/2-1-1-1/1-2-2-2/2-1-1-1//1out1in; } \\
\text { GB2:2-3-3-3/2-1-1-1/2-3-3-3/2-1-1-1/1-2-2-2/2-1-1-1/0-1-1-1/1-2-2-2/0-1-1- } \\
\text { 1/1-2-2-2/2-1-1-1/1-2-2-2//1in1out; } \\
\text { GB3: 1-0-1-2/2-3-2-1//Full in; } \\
\text { GB4:2-2-2-3/2-2-2-1/2-2-2-3/2-2-2-1/1-1-1-2/2-2-2-1/0-0-0-1/1-1-1-2/0-0-0- } \\
\text { 1/1-1-1-2/2-2-2-1/1-1-1-2//1in1out; } \\
\text { GB5:1-1-1-0/1-1-1-2/1-1-1-0/1-1-1-2/2-2-2-1/0-0-1-2/3-3-3-2/2-2-2-1/3-3-3- } \\
\text { 2/2-2-2-1/1-1-1-2/2-2-2-1//1 out1in. }\end{array}$ & $\begin{array}{l}\text { 300D96f polyester } \\
\text { 300D96f polyester } \\
\text { 400D polyester monofilament } \\
\text { 300D96f polyester } \\
\text { 300D96f polyester }\end{array}$ \\
\hline 10 & $\begin{array}{l}\text { GB1:1-0-0-0/0-1-1-1//Full in; } \\
\text { GB2:3-3-3-3/0-0-0-0//Full in; } \\
\text { GB3:1-0-1-2/2-3-2-1//Full in; } \\
\text { GB4: 3-3-3-3/0-0-0-0//Full in; } \\
\text { GB5:1-1-1-0/0-0-0-1//Full in. }\end{array}$ & $\begin{array}{l}\text { 300D96f polyester } \\
\text { 300D96f polyester } \\
\text { 400D polyester monofilament } \\
\text { 300D96f polyester } \\
\text { 300D96f polyester }\end{array}$ \\
\hline 11 & $\begin{array}{c}\text { GB1:0-0-0-0/2-2-2-2/1-1-1-1/3-3-3-3/1-1-1-1/2-2-2-2//Full in; } \\
\text { GB2:1-0-0-0/0-1-1-1//Full in; } \\
\text { GB3:1-0-5-4/8-9-4-5//1in1out; } \\
\text { GB4:8-9-4-5/1-0-5-4//1out1i; } \\
\text { GB5:1-1-1-0/0-0-0-1//Full in; } \\
\text { GB6:0-0-0-0/2-2-2-2/1-1-1-1/3-3-3-3/1-1-1-1/2-2-2-2//Full in. }\end{array}$ & $\begin{array}{l}\text { 300D96f polyester } \\
\text { 300D96f polyester } \\
\text { 400D polyester monofilament } \\
\text { 400D polyester monofilament } \\
\text { 300D96f polyester } \\
\text { 300D96f polyester. }\end{array}$ \\
\hline 12 & $\begin{array}{l}\text { GB1:1-0-0-0/1-2-2-2/2-3-0-0/2-1-2-2//1in1out; } \\
\text { GB2:2-3-0-0/2-1-2-2/1-0-0-0/1-2-2-2//1out1in; } \\
\text { GB3:1-0-1-2/2-3-2-1//1in1out; } \\
\text { GB4:2-3-2-1/1-0-1-2//1out1in; } \\
\text { GB5:1-0-0-0/1-2-2-2/2-3-0-0/2-1-2-2//1in1out; } \\
\text { GB6:2-3-0-0/2-1-2-2/1-0-0-0/1-2-2-2//1out1in. }\end{array}$ & $\begin{array}{l}\text { 300D96f polyester } \\
\text { 300D96f polyester } \\
\text { 400D polyester monofilament } \\
\text { 400D polyester monofilament } \\
\text { 300D96f polyester } \\
\text { 300D96f polyester }\end{array}$ \\
\hline
\end{tabular}




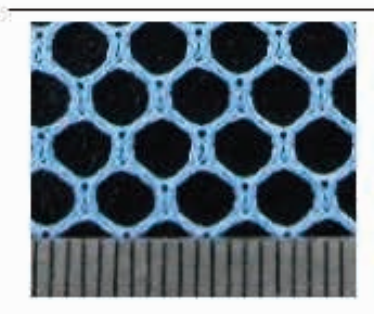

(a-1) no. 1-face

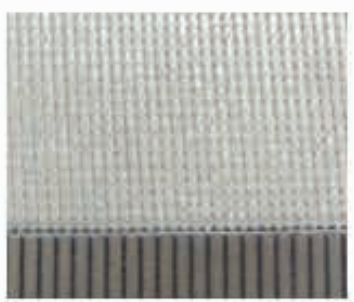

(c-1) no. 3-face

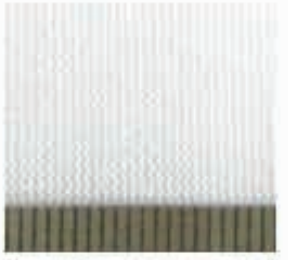

(e-1) no. 5-face

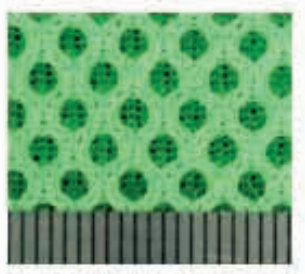

(g-1) no. 7-face

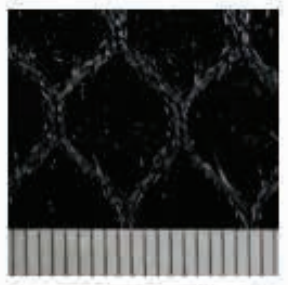

(i-1) no. 9-face

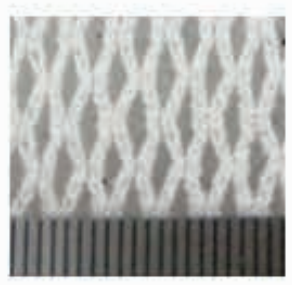

(k-1) no. 11-face
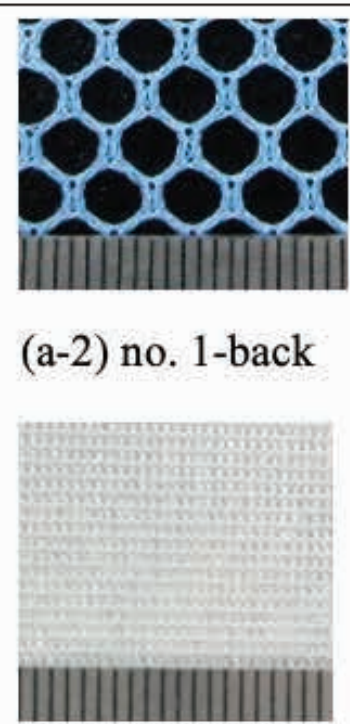

(c-2) no. 3-back

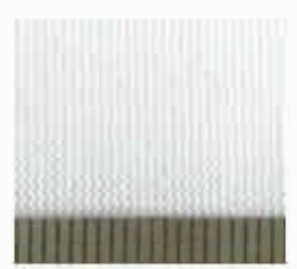

(e-2) no. 5-back
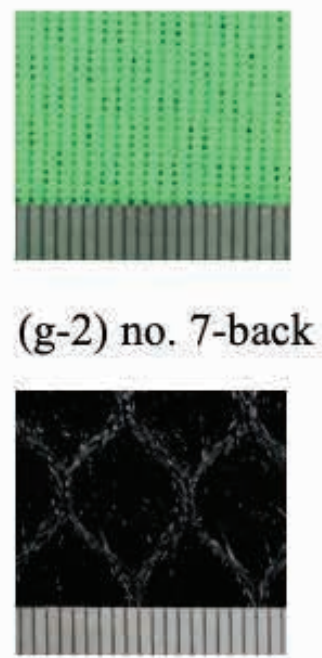

(i-2) no. 9-back

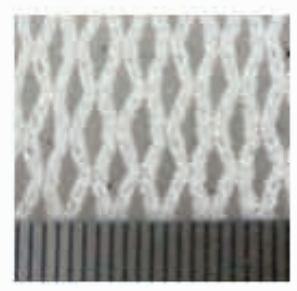

(k-2)) no. 11-back

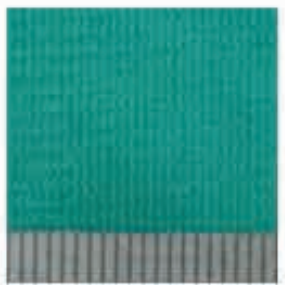

(b-1) no. 2-face

(b-2) no. 2-back
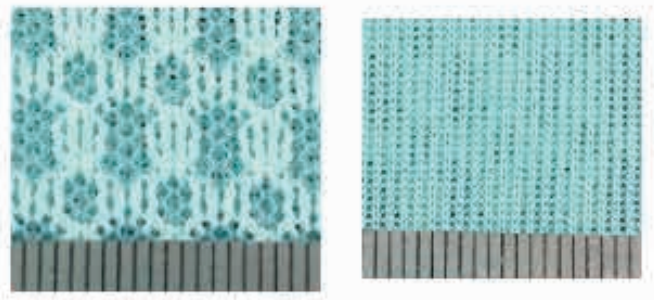

(d-2) no. 4-back

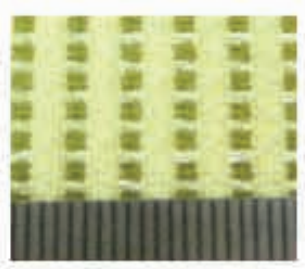

(f-1) no. 6-face

(f-2) no. 6-back

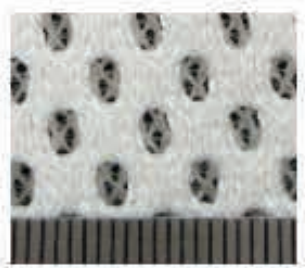

(h-1) no. 8-face
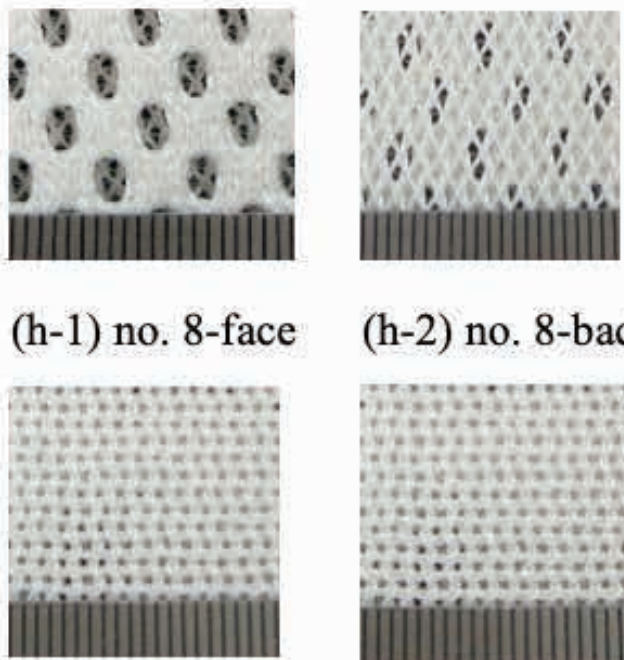

(h-2) no. 8-back

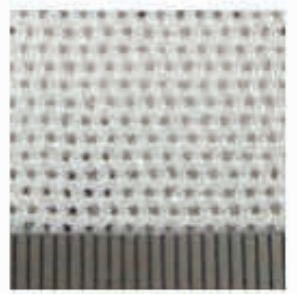

(j-1) no. 10-face
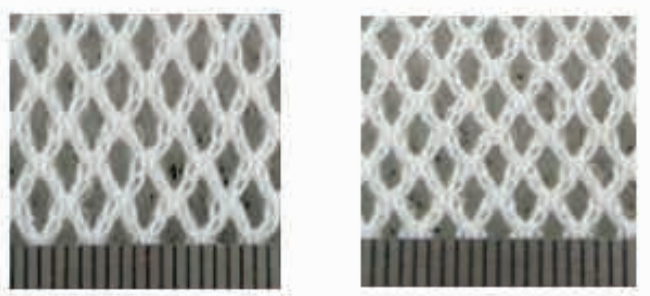

(1-2) no. 12-back

Figure 1. Photos of warp-knitted fabric 


\subsection{Test method}

\subsubsection{Water vapor permeability}

Water vapor permeability was measured using textile measurement method according to the China standard GB/T 127042-2009. As for double-sided fabrics, the side with mesh structure was viewed as the face side and the face with plain structure was viewed as the back side. Fabric samples and water were conditioned at least 1 day in the environment with temperature $20 \pm 2{ }^{\circ} \mathrm{C}$ and the relative humidity $65 \pm 2 \%$. The amount of $10 \mathrm{ml}$ water was filled into the cup, each sample was poured in the cup, and each permeability cup was sealed with tape. The radius of cup is $3 \mathrm{~cm}$. The cup and fabric were weighted as an original weight of assembly (M1), and $24 \mathrm{~h}$ later the total weight of cup and fabric was measured (M2). Three pieces of each sample were tested. The average values were calculated by the following equation.

Water vapor permeability $=\frac{M 2-M 1}{A \cdot t}$

where $A$ is the fabric sample tested area and $t$ is $24 \mathrm{~h}$. All the fabrics were tested with the face side up and the back side up, respectively. According to the quality mass of every square meter of fabric 1 day later, the greater the value the better the fabric moisture permeability.

\subsubsection{Air permeability}

Air permeability test was confirmed with the principle that the permeability was determined by the difference of pressure on both sides of the fabric and the air flow rate though the fabric. According to the China standard of GB/T 5453-1997 (the determination of textile fabric permeability), $Y G(B) 461 E$ was used to measure the air permeability of fabrics. The results were shown on apparatus directly. The area of the fabric sample is $20 \mathrm{~cm}^{2}$, and the pressure drop of $100 \mathrm{~Pa}$ on both sides of the fabric sample is selected. All the fabrics were tested with the face side up and the back side up, respectively. Since fabric nos. 11 and 12 were too thick to be hold by the testing instrument, these two fabrics cannot be tested.

\subsubsection{Water absorption ratio}

Water absorption capacity was tested according to China standard GB 21655.1Y2008. The dry weight of fabric $(10 \mathrm{~cm} \times 10 \mathrm{~cm})$ was measured and the fabric was immersed into a bath of distilled water for $5 \mathrm{~min}$. Then, the fabric was hanged vertically till no water droplet dripped within $30 \mathrm{~s}$. By that time, the fabric was weighed again. The calculation of water absorption ratio is calculated by the following equation.

$$
A=\frac{m-m_{0}}{m_{0}} \times 100 \%
$$

where $A$ is water absorption (\%), $m_{0}$ is dry weight $(\mathrm{g})$, and $m$ is wet weight $(\mathrm{g})$.

\subsubsection{Thermal insulation ratio and heat transfer coefficient}

According to the China standard GB 11048-1989 testing method for warmth retention property of textiles, the samples $(30 \mathrm{~cm} \times 30 \mathrm{~cm}$ ) were tested on a hot-plate instrument (YG 606D). The hot plate was covered with the tested sample. Since the hot plate, the surrounding protective plate, and the bottom plate were controlled by electric heating at a constant temperature $\left(33^{\circ} \mathrm{C}\right)$ by means of power on and off, the heat of the hot plate can only be dissipated in the direction of the sample. The heating time required for the hot plate to maintain a constant temperature within the specified time was measured, and then the thermal insulation ratio and heat transfer coefficient were calculated. The thermal insulation ratio $(Q)$ and heat transfer coefficient (U2) were obtained by the instrument. The calculations of these two parameters are given as follows.

$$
Q=\frac{Q_{1}-Q_{2}}{Q_{1}} \times 100 \%
$$

$Q(\%)$ is thermal insulation ratio; $Q_{1}\left(\mathrm{~W} /{ }^{\circ} \mathrm{C}\right)$ is heat transfer of hot plate without sample without sample; and $Q_{2}\left(\mathrm{~W} /{ }^{\circ} \mathrm{C}\right)$ is heat transfer of hot plate without sample with sample.

$U_{2}=\frac{U_{\mathrm{bp} .} U_{1}}{U_{\mathrm{bp}}-U_{1}}$

$U_{2}\left(\mathrm{~W} /\left(\mathrm{m}^{\left.2 \cdot{ }^{\circ} \mathrm{C}\right)}\right)\right.$ is heat transfer coefficient; $U_{\mathrm{bp}}\left(\mathrm{W} /\left(\mathrm{m}^{\left.2 \cdot{ }^{\circ} \mathrm{C}\right)}\right)\right.$ is heat transfer coefficient of hot plate without sample; and $U_{1}(\mathrm{~W} /$

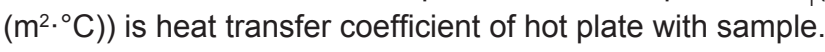

\section{Results and Discussion}

\subsection{Water vapor permeability}

The result of water vapor permeability test of all samples was shown in Figure 2. Fabric no. 1 had the highest water vapor permeability ( $339.28 \mathrm{~g} / \mathrm{m}^{2}$. day) due to its larger mesh structure and single layer. Fabric nos. 11 and 12 had the highest thickness $(20 \mathrm{~mm})$ and so the lowest water vapor permeability (248.8 and $244.2 \mathrm{~g} / \mathrm{m}^{2}$.day) among spacer fabrics. This might be that spacer fabric with large pores that determine the lowest volume density $\left(79.3\right.$ and $\left.78.5 \mathrm{~kg} / \mathrm{m}^{3}\right)$ and highest porosity $(94.25 \%$ and $94.31 \%)$ cannot transmit water vapor faster due to more still air hold in transverse section.

Fabric nos. 9 and 10 got similar thickness $(7.42$ and $7.68 \mathrm{~mm}$, respectively), but the water vapor permeability of fabric no. 9 was better. It was because fabric no. 9 had larger mesh on both sides and lower loop density compared with fabric no. 10 . On the other hand, fabric nos. 2 and 3 had lower thickness $(0.21$ and $0.24 \mathrm{~mm}$ ) but had similar water vapor permeability (302.39 and $322.20 \mathrm{~g} / \mathrm{m}^{2}$.day) when compared with fabric no. 9 with much higher thickness.

As for fabric nos. 4, 5, 7, and 8, they had similar thickness (from 2.56 to $2.91 \mathrm{~mm}$ ), but water vapor permeability of fabric nos. 4 and $5\left(270.5\right.$ and $276.5 \mathrm{~g} / \mathrm{m}^{2}$. day) was higher than fabric nos. 7 and 8 (255.8 and $259.5 \mathrm{~g} / \mathrm{m}^{2}$. day). It was probably that volume density of fabric nos. 7 and $8\left(159.22\right.$ and $\left.166.63 \mathrm{~kg} / \mathrm{m}^{3}\right)$ was 


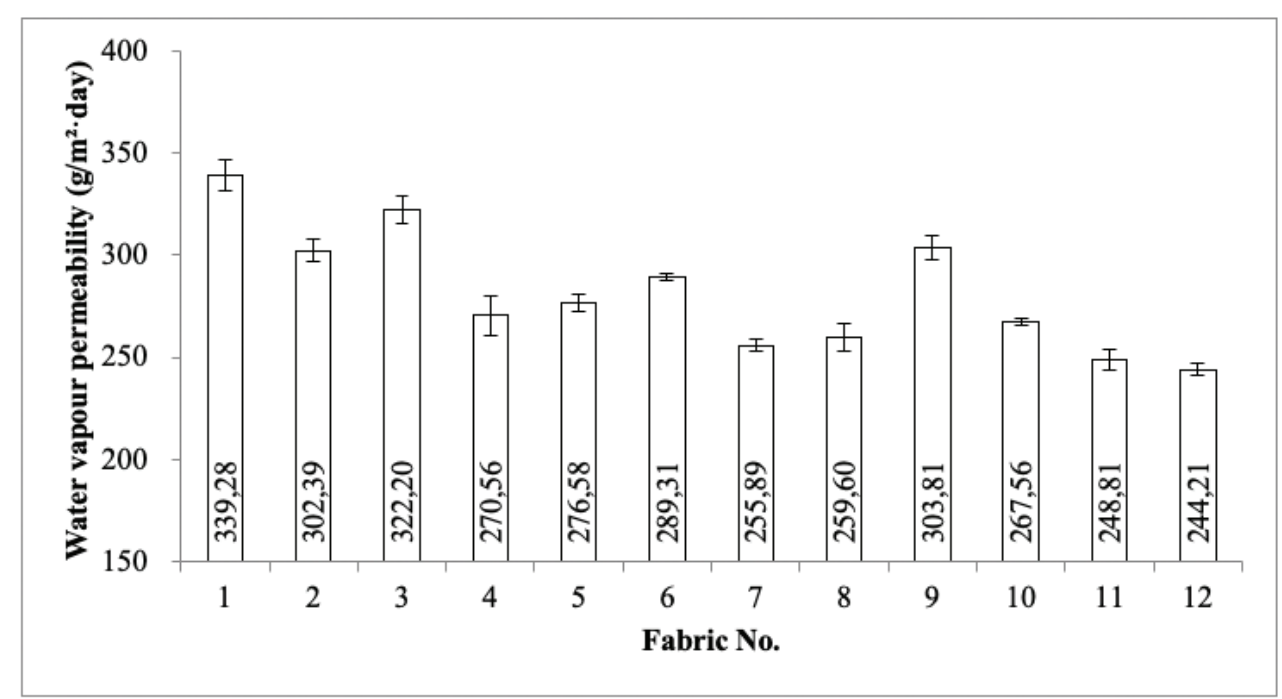

Figure 2. Water vapor permeability of all samples.

higher than fabric nos. 4 and $5\left(96.62\right.$ and $\left.92.63 \mathrm{~kg} / \mathrm{m}^{3}\right)$, and the porosity of fabric nos. 7 and $8(88.46 \%$ and $87.93 \%)$ was lower than fabric nos. 4 and 5 (93 and 93.29\%).

In Figure 3, fabric nos. 4 and 6-8 had mesh structure on the face side and plain structure on the back side. In this case, the fabrics were tested with both face side up and with back side up conditions. The water vapor permeability under the mesh side down condition (i.e., mesh side near the water surface) was higher than that under the plain side down condition (i.e., plain side close to the water surface). There were 8.82 and $2.76 \%$ differences for fabric no. 4 and 6 when the fabric was tested reversely. It was suggested that the surface of fabric worn nearby the skin of human body could affect the water vapor transmission through garment. Under the condition of the same fabric thickness and other various factors, when the surface with mesh is nearby water surface during test, the spacer fabric had better water vapor permeability.

\subsection{Air permeability}

It can be found that the air permeability of fabric no. 9 was the highest $(6,439.052 \mathrm{~mm} / \mathrm{s})$ even compared with fabric no. 1 that

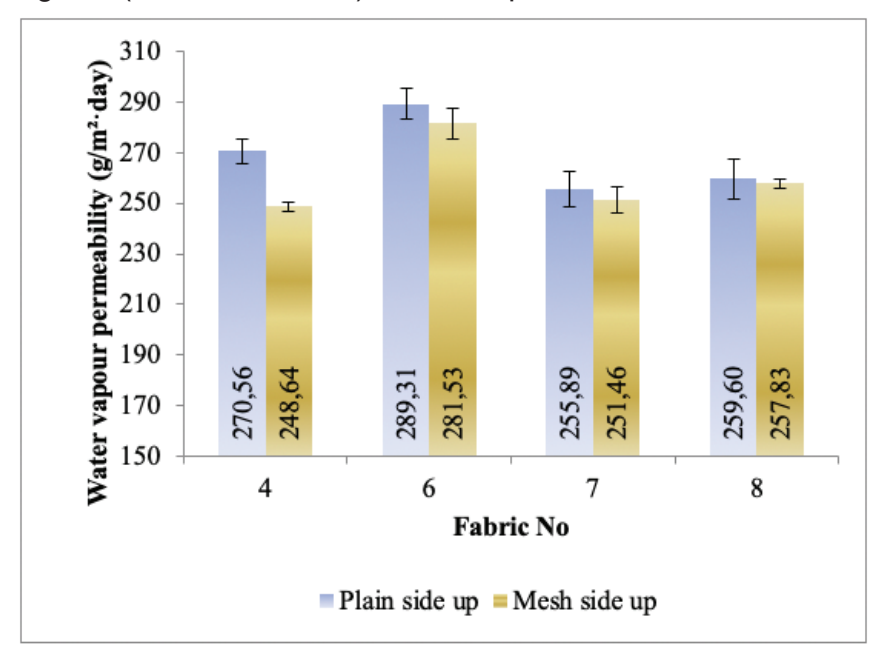

Figure 3. Water vapor permeability of samples that have different surfaces. had single layer with larger mesh (see Figure 4). Since fabric no. 9 had large mesh structure on both sides (see Figure 1), it had the lowest loop density and lower volume density among spacer fabrics. Due to the larger mesh size, spacer fabric no. 9 had slightly higher air permeability than single layer mesh fabric no. 1.

The air permeability of fabric no. 2 was the lowest $(966.9 \mathrm{~mm} / \mathrm{s})$. This was because fabric no. 2 was plain warp-knitted fabric with highest loop density (448 loop number/ $\mathrm{cm}^{2}$ ) and dense structure although it was the thinnest $(0.21 \mathrm{~mm})$ among all the tested fabrics.

The air permeability of spacer fabrics no. 5 and 10 were comparatively low which was around $1,960 \mathrm{~mm} / \mathrm{s}$ due to plain structure on both sides. Although the thickness of fabric nos. $4,5,7$, and 8 was from 2.56 to $2.91 \mathrm{~mm}$, air permeability of fabric nos. 4 and 5 (2,743.16 and 1,960.02 mm/s) was lower than fabric nos. 7 and $8(3,111.35$ and $3,025.55 \mathrm{~mm} / \mathrm{s})$. It was because the loop density and porosity of fabric nos. 4 and 5 were higher than that of fabric nos. 7 and 8.

All the fabrics were tested for both face side up and back side up conditions. It can be seen from Figure 5 that when the plain side of fabric nos. 4 and $6-8$ was up during test, air permeability was better than that with the mesh side up. There were 10.76 and $14.19 \%$ differences for fabric nos. 6 and 7 when the fabric was tested reversely. It was suggested that the surface structure of fabric had an effect on air permeability. As for fabrics that had mesh structure on the one side and plain structure on the other side, when mesh side was up during test, they had better air permeability. It was suggested that fabric with mesh structure should be used as inner side for clothing or used as mattress under some conditions.

\subsection{Water absorption ratio}

As shown in Figure 6, fabric no. 8 had the highest water absorption ratio (175.44\%). This was because it had the highest volume density $\left(166.63 \mathrm{~kg} / \mathrm{m}^{3}\right)$ among the nine spacer fabrics. Fabric no. 5 had higher water absorption because it had plain 


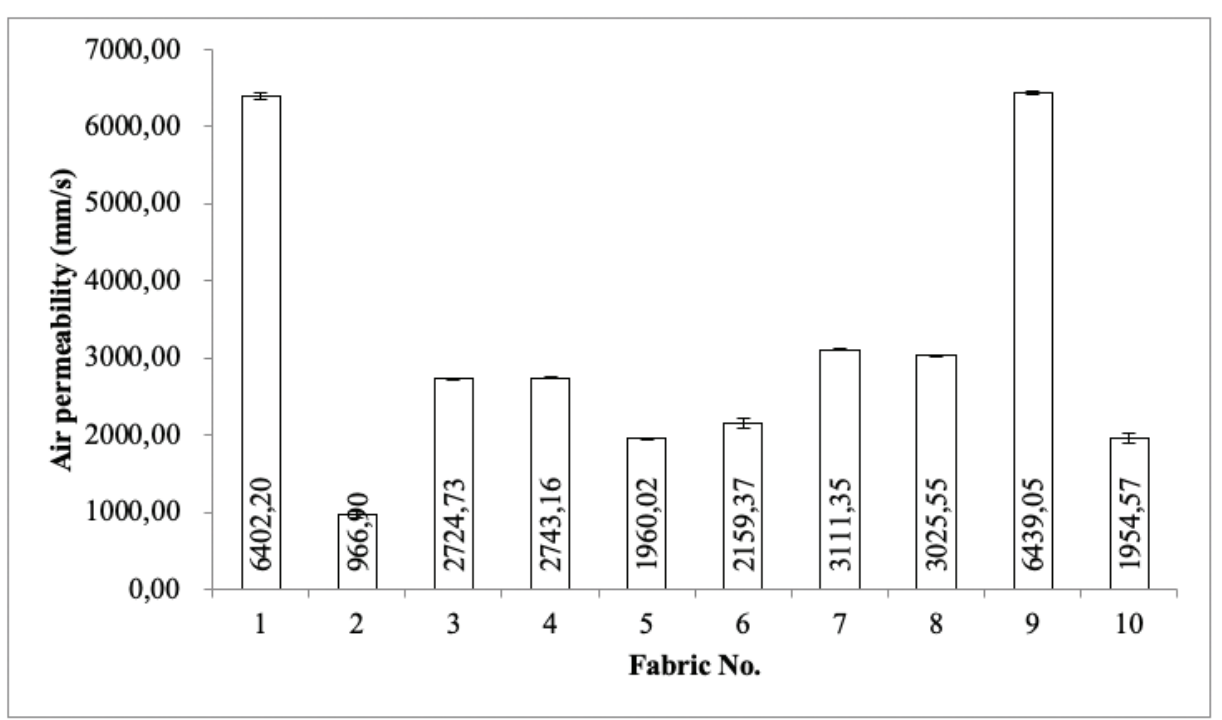

Figure 4. Air permeability of all samples.

structure on both sides with the highest loop density (300 loop number $/ \mathrm{cm}^{2}$ ) among the nine spacer fabrics. Therefore, it revealed that fabrics with higher volume density could exhibit better water absorption.

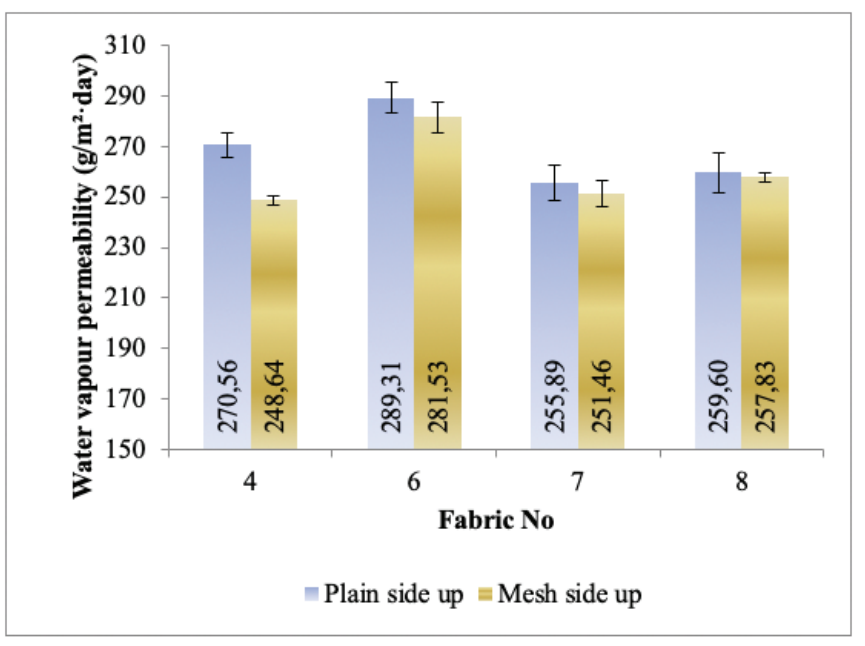

Figure 5. Air permeability of spacer fabrics that have different surfaces.
The water absorption ratio of different fabrics was shown in Figure 6. Fabric nos. 9-12 with higher thickness $(7.42-20 \mathrm{~mm})$ had relatively lower water absorption ratio (40.69-77.4\%). This was likely because those fabrics had higher porosity (91.41$94.25 \%)$ and lower loop density (20-56 number/cm ${ }^{2}$ ). Fabric no. 9 had the lowest water absorption but had the highest air permeability. It was because there were much large voids on both sides that cannot hold much water. Fabric nos. 9 and 10 had similar thickness $(7.42$ and $7.68 \mathrm{~mm})$ with different water absorptions ( 40.7 and $77.4 \%$ ), and the primary reason was that fabric no. 10 had more filaments in unit area to absorb water and higher loop density. Although fabric nos. 11 and 12 had highest fabric mass, it was observed that relative lower water absorption (42.43-46.11\%) due to its large void on both sides, poor water absorption ability of monofilament, and lowest volume density $\left(79.3\right.$ and $\left.78.5 \mathrm{~kg} / \mathrm{m}^{3}\right)$.

\subsection{Thermal insulation ratio and heat transfer coefficient}

As shown in Figure $7 \mathrm{a}$, the thermal insulation ratio of spacer fabrics was 5-16 times higher than that of normal fabrics. It

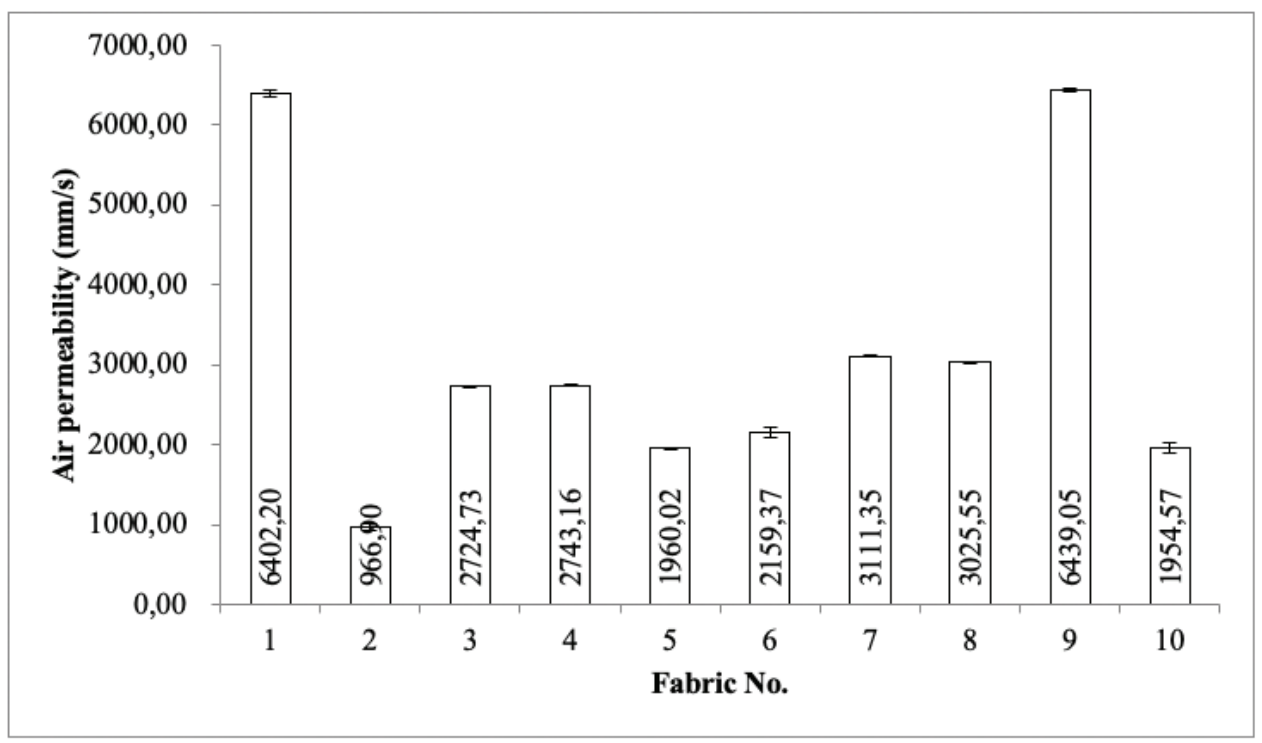

Figure 6. Water absorption ratio of different fabrics. 


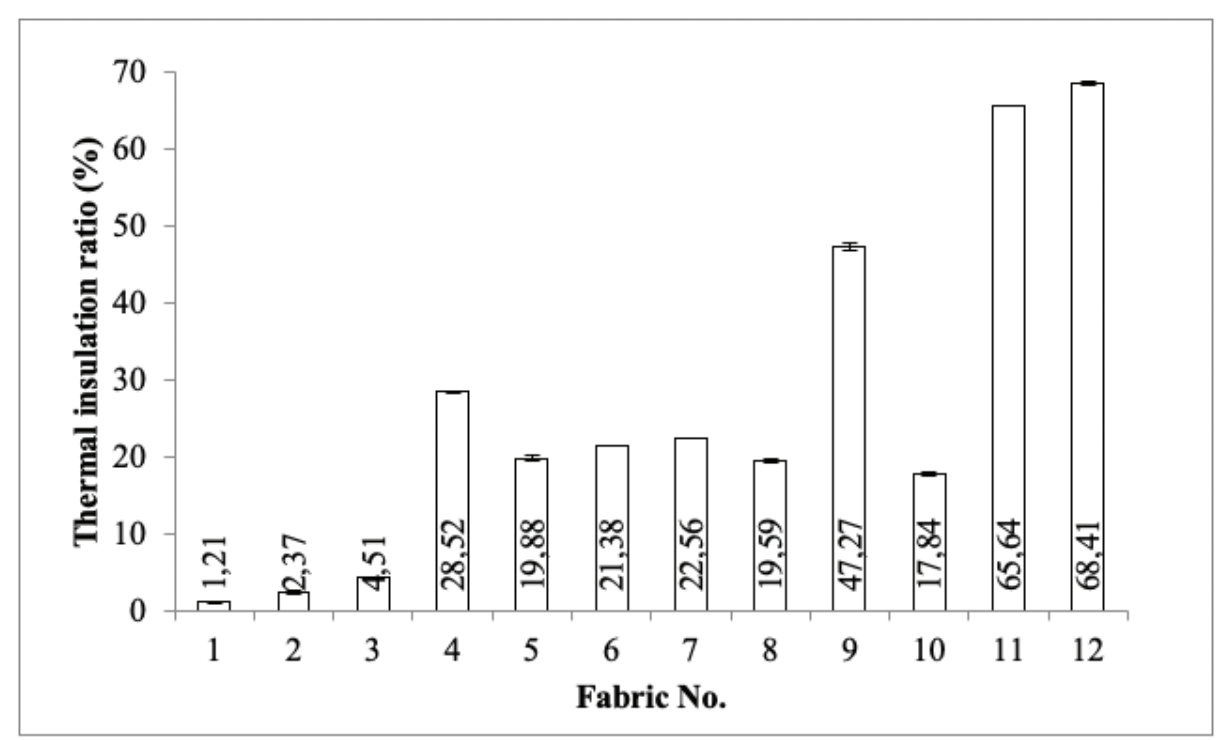

(a)

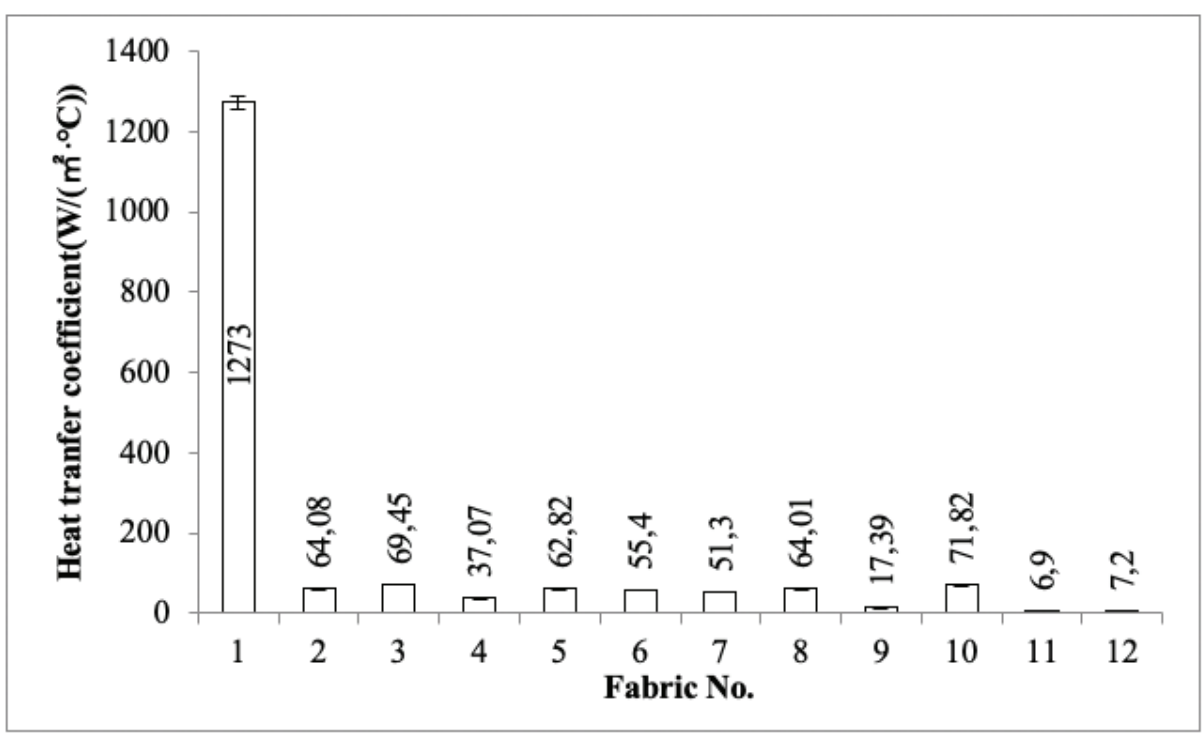

(b)

Figure 7. (a) Thermal insulation ratio and (b) heat transfer coefficient.

was demonstrated that spacer fabrics had better thermal insulation property. Among the spacer fabrics with similar thickness (2.56-3.37 mm) (i.e., fabric nos. 4-8), the testing results ranged from 19.59 to $28.22 \%$. For thickest fabric nos. 11 and 12 , the thermal insulation ratio was $65-68 \%$.

The heat transfer coefficient of all knitted fabrics was shown in Figure $7 \mathrm{~b}$. Fabric no. 1 exhibited higher heat transfer due to its big mesh structure and single layer. Fabric nos. 11 and 12 had the lowest values among various samples, because they had the highest thickness. To compare fabric no. 9 with 10 under similar thickness, the former one had lower value. This might be that they had much larger mesh size on both surfaces, which could decrease the number of heat transfer channel. The heat transfer coefficient of other spacer fabrics and single-layered fabrics ranged from 37.07 to $71.82 \%$.

\subsection{Pearson correlation analysis for warp-knitted spacer fabrics}

\subsubsection{Relationship among the testing indexes}

According to Table 3, water vapor permeability was significantly correlated with air permeability with correlation coefficient at 0.762 . It indicated that the higher water vapor permeability was partially associated with higher air permeability.

Thermal insulation ratio was highly and significantly correlated with heat transfer coefficient at -0.958 . It was demonstrated that higher thermal insulation could determine the lower heat transfer. Thermal insulation ratio was highly and significantly correlated with air permeability at 0.941 . It was suggested that spacer fabrics with higher air permeability could trap more air through thickness, which resulted in the higher thermal insulation ratio. Thermal insulation ratio was negatively correlated with water absorption ratio at 0.77 . Heat transfer 
Table 3. Correlations between tests and fabric parameter

\begin{tabular}{|c|c|c|c|c|c|c|c|c|c|c|}
\hline \multicolumn{11}{|c|}{ Correlations } \\
\hline & Vapor & Air & Water & Thermal & Heat & Mass & Thickness & Volume & Loop & Porosity \\
\hline Vapor & 1 & & & & & & & & & \\
\hline Air & $0.762^{*}$ & 1 & & & & & & & & \\
\hline Water & 0.286 & -0.610 & 1 & & & & & & & \\
\hline Thermal & -0.362 & $0.941^{* *}$ & $-0.770^{*}$ & 1 & & & & & & \\
\hline Heat & 0.257 & $-0.853^{*}$ & $0.736^{*}$ & $-0.958^{* *}$ & 1 & & & & & \\
\hline Mass & -0.510 & 0.336 & $-0.797^{*}$ & $0.860^{* *}$ & $-0.699^{*}$ & 1 & & & & \\
\hline Thickness & -0.542 & 0.458 & $-0.769^{*}$ & $0.917^{\star *}$ & $-0.776^{*}$ & $0.982^{\star *}$ & 1 & & & \\
\hline Volume & 0.269 & -0.126 & 0.525 & $-0.683^{*}$ & 0.658 & -0.518 & -0.637 & 1 & & \\
\hline Loop & -0.047 & -0.547 & 0.639 & -0.498 & 0.450 & -0.623 & -0.517 & -0.030 & 1 & \\
\hline Porosity & -0.269 & 0.125 & -0.525 & $0.683^{*}$ & -0.658 & 0.518 & 0.637 & $-1.000^{* *}$ & 0.031 & 1 \\
\hline
\end{tabular}

${ }^{*}$ Correlation is significant at the 0.05 level (two-tailed).

${ }^{* *}$ Correlation is significant at the 0.01 level (two-tailed).

Notes: "Vapor" represents water vapor permeability. "Air" represents air permeability. "Water" represents water absorption ratio.

"Thermal" represents thermal insulation ratio. "Heat" represents heat transfer coefficient.

coefficient was correlated with air permeability at -0.853 and water absorption ratio at 0.736 . This reflected the air permeability and thermal property that were determined by the pore size and pore number associated with the air flow.

\subsubsection{Relationship between the testing indexes and fabric parameters}

For warp-knitted spacer fabrics, mass and thickness were highly and significantly correlated with each other at 0.982 . Porosity was negatively and significantly correlated with volume density (correlation coefficient $=-1$ ).

Thermal insulation ratio was much highly correlated with thickness at 0.917 , mass at 0.86 , volume density at -0.683 , and porosity at 0.683 . Heat transfer coefficient significantly was correlated with thickness at -0.776 and mass at -0.699 . Water absorption ratio was negatively correlated with mass at -0.797 and thickness at -0.769 .

\subsection{Principal component analysis for warp-knitted spacer fabrics}

There were five indexes obtained by four testing methods. The principal component analysis was conducted to establish a linear combination of the variables for heat and mass transfer of warp-knitted spacer fabrics. Only one factor (Eignevalue >1) was calculated out of five indexes with cumulative at $74.692 \%$.

The statistical mode was established as follows:

The heat and mass transfer of spacer fabric $=0.726 \mathrm{x}$ vapor permeability $+0.976 \times$ air permeability $-0.672 \times$ water absorption ratio $+0.988 \times$ thermal insulation ratio $-0.91 \times$ heat transfer coefficient.
After calculation, the fabric no. 9 had the highest score in comprehensive assessment. The rank of other spacer fabrics is fabric nos. $10,8,7,5,6,12$, and 11 from high to low score (see Table 4).

Table 5 shows the total influence on a single variable for all factors. It can been seen that water vapor permeability, air permeability, water absorption ratio, thermal insulation ratio, and heat transfer coefficient attribute to this model at 52.6, $95.2,45.1,97.7$, and $82.8 \%$, respectively.

\section{Conclusions}

In this study, spacer warp-knitted fabrics with thickness at 2-20 $\mathrm{mm}$ were compared with the normal warp-knitted fabrics and themselves. Water vapor permeability of spacer varied from 244.21 to $303.81 \mathrm{~g} / \mathrm{m}^{2}$. day and air permeability

Table 4. Comprehensive assessment according to statistical mode

\begin{tabular}{|c|c|c|}
\hline Fabric no. & Calculated score & Rank \\
\hline 4 & 2,776 & 9 \\
\hline 5 & $5,476,892$ & 5 \\
\hline 6 & $4,325,986$ & 6 \\
\hline 7 & $6,800,587$ & 4 \\
\hline 8 & $9,511,265$ & 3 \\
\hline 9 & $19,578,741$ & 1 \\
\hline 10 & $12,672,103$ & 2 \\
\hline 11 & $3,980,662$ & 7 \\
\hline 12 & $4,067,258$ & 8 \\
\hline
\end{tabular}


Table 5. Communalities

\begin{tabular}{|c|c|c|}
\hline & Initial & Extraction \\
\hline Vapor & 1.000 & 0.526 \\
\hline Air & 1.000 & 0.952 \\
\hline Water & 1.000 & 0.451 \\
\hline Thermal & 1.000 & 0.977 \\
\hline Heat & 1.000 & 0.828 \\
\hline
\end{tabular}

Extraction method: principal component analysis.

varied from $1,960.02$ to $6,439.05 \mathrm{~mm} / \mathrm{s}$. The highest value of water absorption ratio reached $175.44 \%$. Thermal insulation ratio of spacer between 17.84 and $68.41 \%$ was much higher than normal fabric. Also, spacer fabrics with different surface structures were investigated. As for fabrics with mesh structure at the inner side and plain structure at the outer side, it could provide better water vapor permeability and air resistance. The difference of $8.82 \%$ for water vapor permeability and $14.19 \%$ for air permeability were found when the thickness of spacers was 2.56 and $3.37 \mathrm{~mm}$, respectively.

The water vapor permeability of fabrics increased when thickness decreased and volume density increased within samples in this study. As for fabrics with similar thickness, ones with higher volume density could result in lower water vapor permeability and higher water absorption due to more air contained in spacer fabric and proper pore size.

Mass and thickness were highly and significantly correlated with each other at 0.982 . Thermal insulation ratio was highly and significantly correlated with heat transfer coefficient at -0.958 and with thickness at 0.917 . Thermal insulation ratio is highly and significantly correlated with air permeability at 0.941 .

\section{Acknowledgment}

This work was supported by the Fundamental Research Funds for the Central Universities (2232020 D-45); RGC (PolyU 252029/19E); ITF (ITS/093/19) $\square$ Shanghai style fashion design and value creation knowledge service center (ZX201311000031).

\section{Reference}

[1] Gokarneshan, N. (2015). Design of warp knit spacerfabrics: recent research insights on technical applications. Journal of Textile and Apparel, Technology and Management, 9(3), 1-25.

[2] Tong, S., Yip, J., Yick, K., Yuen, C. M. (2015). Exploring use of warp-knitted spacer fabric as a substitute for the absorbent layer for advanced wound dressing. Textile Research Journal, 85(12), 1258-1268.

[3] Liu, Y., Hu, H. (2011). Compression property and air permeability of weft knitted spacer fabrics. The Journal of the Textile Institute, 102(4), 366-372.

[4] Zhang, X., Yu, Y., Boakye, A., Ma, P. (2018). Compressive properties of high-distance warp-knitted spacer flexible composite. Fibers and Polymers, 19(5), 1135-1142.

[5] Pan, Y., Hsieh, C., Huang, C., Huang, C., Lou, C., et al. (2015). Sound absorbent, flame retardant warp knitting spacer fabrics: Manufacturing techniques and characterization evaluations. Fibers and Polymers, 16(12), 2682-2688.

[6] Buhai, C., Mirela, B., Vlad, L., Rajesh, M. (2013). Comfort properties of functional weft knitted spacer fabrics. TEKSTIL ve KONFEKSIYON, 23(2), 220-227.

[7] Mirela, B., Ramona, C., Arzu, M., Gözde, E., Pınar, Ç. (2015). Investigation of the physical and thermal comfort characteristics of knitted fabrics used for shoe linings. TEKSTIL ve KONFEKSiYON, 25(2), 111-118.

[8] Gözde, E. (2017). Analysis of thermal-physiological comfort and moisture management properties of flat knitted spacer fabrics. TEKSTIL ve KONFEKSIYON 27(3), 241-250.

[9] Gözde, E., Arzu, M. (2011).Heat, air and water vapor transfer properties of circular knitted spacer fabrics. TEKSTIL ve KONFEKSIYON, 4, 369-373.

[10] Mao, N., Russell, S. J. (2007). The thermal insulation properties of spacer fabrics with a mechanically integrated wool fiber surface. Textile Research Journal, 77(12), 914922.

[11] Bagherzadeh, R., Gorji, M., Latifi, M. (2012). Evolution of moisture management behavior of high wicking $3 D$ warp knitted spacer fabrics. Fibers and Polymers, 13(4), 529534.

[12] Dias, T., Delkumburewatte, G. B.(2010). Analysis of water absorbency into knitted spacer structures. The Journal of Textile Institute, 101(2), 143-153.

[13] Sedigheh, B., Safora. S., Seyed, A., Hosseini. R., Mohammad. S., et al. (2005) Computational and experimental investigation of moisture transport of spacer fabrics. Journal of Engineered Fibers and Fabrics, 5(3), 42-48.

[14] Veerakumar, A., Rajesh, M., Jiri, M., Louise, D., Simon. S., (2018). Thermal and water vapor transmission through porous warp knitted $3 D$ spacer fabrics for car upholstery applications. The Journal of the Textile Institute, 109(3), 345-357. 